Pre-publication version. The final published version can be found here: https://www.tandfonline.com/doi/abs/10.1080/14733285.2017.134197

\title{
The Comfort of the River: Understanding the affective geographies of angling waterscapes in young people's coping practices.
}

Dr Natalie Djohari, Dr Adam Brown and Dr Paul Stolk

Substance, Manchester, UK.

Corresponding author: Dr Natalie Djohari, Visiting Research Fellow, Department of Anthropology, Goldsmiths, University of London, SE14 6NW. 07964575508. natalie.djohari@gmail.com

Dr Adam Brown, Substance. 3rd Floor, Fourways House. 57 Hilton Street. Manchester. M1 2EJ. 01612 445418. adam.brown@subsatnce.net

Dr Paul Stolk, Newcastle Business School, University of Newcastle, Callaghan, University Drive, Australia. NSW2308.paul.stolk@newcastle.edu.au

This work was supported by the Big Lottery Fund under Grant number RGT/1/010317196

\section{Acknowledgements}

We would like to thank the Environment Agency, Angling Trust, Get Hooked on Fishing, Angling Development Boards of England and Scotland, and Dr Liz Oughton from Newcastle University (UK) for their support. We would also like to thank the young people who graciously shared their experiences with us. 


\section{The Comfort of the River: understanding the affective geographies of angling waterscapes in young people's coping practices.}

This paper draws on ethnographic research with angling intervention programs working with 'disaffected' young people in the UK to demonstrate how young people use the affective geographies of waterscapes to regulate their feelings and escape stressful lives. But rather than interpret the restorative or therapeutic quality of waterscapes as the consequence of (passive) immersion into green/blue spaces, we argue that 'comfort' is derived from an ongoing, active engagement with(in) the world. Drawing on works influenced by phenomenological theories and relational understandings of the morethan-human world, we illustrate how the affectual qualities of waterscapes are continually 'woven' into being through the material and embodied practices of young anglers. However, understanding why waterscapes 'matter' to young people also requires accounting for those assemblages originating in the past that shape these coexperienced worlds.

Keywords: fishing; safe spaces; embodiment; waterscapes; affect; angling.

The day is warm and I am sitting next to 'Matt' (15) on the bankside. ${ }^{1}$ His friends have drifted off to their own spots around the water and the lake is not particularly busy. Gazing out over the water, in pauses of angling activity and silence, 'Matt'

\footnotetext{
${ }^{1}$ All names have been changed.
} 
recounts how he had been having a stressful time at home and at school recently. Coming to the lake helped deal with this.

It's somewhere to come and focus and get away from everything...I do it to get away from if anything's happening. If bad stuff's happening, I can just come down here, I can escape from everything and it's my space to chill out in, relax and do what you want. (Male 15).

Water has a place in the cultural imagination of many societies. It lends itself to the metaphors we think with and the environments we revere. But a focus on the representational or symbolic can only ever be partial to our understanding of people's relationship to waterscapes. Waterscapes are places to be in. There is a phenomenological experience to be accounted for: the ozone smell of waterfalls (Strang 2015); the feel of salt spray matted into your hair and skin; the damp, oppressive humidity of vegetative ponds in high summer. Our local practices, cultures, landscapes and economies are also shaped through the spatio-temporal ecologies of waters: the rhythms, tempos, and durations that are traced through assemblages, bodies and the affective life of human and non-human in materialised, lived and ongoing processes (Jones 2011a: 2289). Tidalscapes, animal cycles and seasonal changes give rhythm to the practices of dock workers, fishermen, and coastal agriculture; they shape river and coastal defences, industry, and drainage systems (Jones 2011a). Dalby (2007) suggests we therefore need a 'blue theory' to redress the relative absence of water in human geography. This should examine watery geographies as they are entangled in ongoing lived experiences that encompass a range of agencies and materialities, including land, air, ice, or snow (Vannini and Taggart 2014; Routio and Jokinen 2015).

Waterscapes, and the practices associated with them, consequently provide rich opportunity to study the affectual experience and rhythmic patterns of spatial 
engagement within children's geographies. For young anglers, waterscapes are part of an affective geography: safe spaces where they run to seek the comfort of the river when life gets too much and their emotions threaten to overwhelm them. But it is not the waterside location per se that provides refuge, it is angling, as unfolding, embodied practice developed with(in) the environment that is significant. We join Milligan and Bingley's (2007) call to be more cautious of claims that promote the natural environment as restorative or therapeutic space in and of its self, because what people $d o$ in such places, and the prior experiences they have had, will greatly influence the way they are affected by them.

This paper contributes to children's geographies and the literature on therapeutic green/blue spaces by moving beyond description of how young people live with(in) watery landscapes to suggests how they actively bring restorative places into being and derive comfort from them. Through a focus on 'being-in-the world' we advance discussions of young people's therapeutic relationship with the more-than-human world by understanding 'comfort' as something arising from an ongoing relation with(in) the world. In the case of angling, the temporal ecologies (derived from waterscapes, seasonality, fish cycles and movements) intersect with young people's lives to create rythmpatterns and absorbing embodied practices that are utilised to 'escape' mentally and physically from life's pressures. These affectual spaces are co-created with others and emerge through a 'time deep' set of assemblages (Jones 2011b:6). Understanding the practice of 'fishing', young people's claims about 'getting away' and the restorative effects of 'being in nature' from this relational perspective suggests the potential for heterogeneous relationships with green/blue spaces. This we claim begins to unpick the biophilia assumption that a person's (frequently passive) location in nature is inevitably 
therapeutic, and instead calls for greater attention to how, for whom, and in what circumstances young people find comfort in the 'natural world'.

\section{Understanding the affectual qualities of green/blue spaces.}

There is a growing body of literature on the importance of being in nature for health and wellbeing. From the biophilia hypothesis (Kellert and Wilson 1993), to 'nature deficit disorder' (Louv 2008), studies of green exercise (Pretty, Hine and Peacock 2006; Brown, Djohari and Stolk 2012) and care farms (Hine, Peacock, and Pretty, J 2008), being in 'nature' is frequently described as having a positive effect on people's lives. They are restorative of physical and emotional wellbeing (Hartig et al 1993) and are thought to reduce attention fatigue (Kaplan 2001). Much of this work has sought to prove and quantify such benefits. However, there is less attention on how personal histories and interactions with(in) these environments shape outcomes. Consequently, the beneficial impact of 'being in nature' appears to originate from a passive relationship between bodies and landscapes that implies a uniformity of experience and therapeutic application. To counter this tendency, this article explores two interconnected lines of inquiry: a phenomenological approach that foregrounds affective geographies that emerge from 'being' or 'becoming-in-the-world' (Merlau-Ponty 1945; Heidegger 1953; Anderson 2012); and an understanding of how place is crafted through embodied practice (Csordas 1994; Ingold 2000; Thrift 2004). Drawing on this scholarly work we have identified four key themes that guide our analysis and prove useful for rethinking how green/blue spaces become 'comforting'.

Firstly, we recognise space as 'unfinished' and ongoing, produced out of our relationships with(in) the world. It is through inhabiting the world that it becomes meaningful for us, what Ingold describes as 'dwelling' (Ingold 2000, 173), or Heidigger's (1956) ‘being-in-the-world'. Edward Soja's (1996) 'thirdspace’ or Casey’s 
(2001) 'place-world' likewise describes the lived and experienced social and historical place as a changing spatiality that we live through. Spaces are always becoming, interacting, transforming and being transformed by the bodies moving through them in a state of 'on-goingness' (Kraftl and Horton 2006, 85; Anderson 2012).

Secondly, there is an affective quality to 'being' with(in) spaces. It is a 'felt' experience that lingers in sensory recall, embodied memories and the 'feelings' we associate with locations (Casey 2001). Attuning to this affectual experience is particularly important for understanding children and young people's geographies because they often describe place in relation to how they 'feel', as an expression of why places matter to them (a focus on being) rather than the representational meanings associated with them (Horton 2010; Pyyry 2016). What matters can have 'meaning' but the relationship is not always linear and things can also matter in the moment of doing it even if there is little meaning attributed to it (Horton 2010). In childhood research, the focus on 'meaning', as opposed to mattering, often prioritises 'knowing' epitomised through language and communication, tending to privilege adult interpretations from parents, teachers or researcher (Rautio and Jokinen 2015). Refocusing on affect and mattering can offer a counter perspective.

Third, what we 'do' in space shapes our experience of them. Spaces are bought into being through people's interactions and sensorial relationships with the materialities and non-human agencies of the world. This is clearest in the literature on embodied practices situated with(in) localised environments. Hill and Plath's work on Japanese clam divers (1998), Ingold on hunter gathers (2000) and the edited volume with Vergunst on Ways of walking (2008), demonstrate how practices develop through our physical, sensorial relationships with(in) the world. We also respond to the materiality of the world through the tools and materials we use, most evident in the 
literature around craftsmanship (Keller and Keller 1993; O’Connor 2007). The world is therefore continually coming into being around us through our material engagement with(in) it, a process Ingold describes as 'weaving' (Ingold 2000, 348) or Anderson describes as 'practice-centred becomings' (Anderson 2012, 575). We see this in Anderson's (2012) description of how the assemblages between people, boards and water converge to fuse the temporal space of the 'surfed wave' into an 'entity/process'; in Pyyry's description of 'hanging out' at the mall as an interactive mingling with one's material surroundings, a form of 'dwelling' through which young people claim the unfolding space (Pyyry 2016: 15); and here, angling practice as rhythmic, embodied engagement with the materialities of the world that weaves into being the affective quality of waterscapes.

Finally, the assemblages (Deleuze and Guttari 1981) that contribute to affectual spaces are 'time deep' (Jones 2011b) and interpersonal. To understand 'comforting' space requires looking not only at an individual's immediate relationship with(in) the environment, but also those assemblages that emerge in the 'trajectories of the past' (Jones 2011b), that shape memories, hopes and expectations developed in the presence and absence of others. This point is important to counter the potential for 'presentism' and the privileging of the individual in analysis that focus on the phenomenological, somatic and non-representational theory (Jones 2011b).

Angling spaces are 'inter-generational' in that they provide opportunities for young people to interact and form relationships usually curtailed by the age segregated environments found in everyday life (Hopkins and Pain 2007; Vanderbeck 2008). This feature is recognised in angling and promoted as a means of improving community cohesion (Djohari 2012; Djohari, Brown and Stolk 2016; Siebers et al 2014). However, in this paper we are concerned with the quality of (intergenerational) relationships 
(Horton and Kraftl 2008) as they relate to crafting the affectual spaces of angling, rather than focusing on how these spaces shape age identities (Hopkins and Pain 2007; Tarrant 2010). Coaching staff and other anglers co-create anglings spaces by 'teaching' young people to weave waterscapes from a particular perspective. But waterscapes also 'matter' because of the felt experience of 'being in' and co-weaving the world with meaningful others.

Using the four theoretical points outlined above, we illuminate how the restorative, 'comforting' spaces experienced by young anglers are not the consequence of a passive location in waterscapes, but are continually emerging and being remade though young people's ongoing, active interactions with(in) the world. We cannot therefore assume a therapeutic quality to 'being in nature' but recognise instead how young people's experience of the more-than-human world differs according to the assemblages and weaving practices that bring these lived locations into presence. This article demonstrates this though research with angling based youth intervention programmes in the UK. It will describe the affective practice of angling and how young people weave waterscapes into 'safe spaces', seeking comfort in the rythmpatterns of engagement and co-experienced worlds.

\section{Methodology: Conducting research in young people's 'safe spaces'.}

This paper draws on two years ethnographic research conducted May 2009 to September 2011 with angling-based intervention programs working with 'disaffected' young people aged 11-25 in the UK. It was part of a larger Big Lottery funded research programme exploring The Social and Community Benefits of Angling. The research was principally orientated to influencing policy and practice, and included action research 
with angling based youth intervention charity Get Hooked On Fishing (GHOF). ${ }^{2}$ Four GHOF project sites across north England served as principle ethnographic case studies. This was supplemented by observational visits and interviews at all the GHOF projects and at GHOF events. Further visits were made to 25 other angling intervention programs, junior angling clubs and family fishing events. In total 436 hours were spent observing delivery across 98 site visits, speaking with 188 young people and 248 adults, including project workers, angling coaches, teachers, and parents. Fieldwork was carried out by a single female researcher providing consistency and familiarity for project staff and young people.

Site visits included young people fishing at freshwater and sea venues, across coarse, sea and game angling. Research observation frequently lasted 5-6 hours including set up, packing away, and accompanying staff and young people to and from venues. Interviews and informal discussions typically occurred at the waterside, synchronised to the ebb and flow of activity. Site visits also included classroom observations both within schools and in intervention projects' own 'classroom' spaces. Field data was recorded through a combination of field notes, audio recorded interviews, photographs and video clips and analysed through qualitative analysis software alongside literature and promotional materials produced by the various angling intervention organisations under study.

Our principal case study organisation, GHOF, was established in 2000 by Mick Watson. GHOF pioneered the use of angling as a 'tool' for intervention work, expanding from a single project in 2000 to 13 projects across England, Scotland and Wales by 2011. What began as a diversionary programme targeting antisocial

\footnotetext{
${ }^{2}$ www.ghof.org.uk
} 
behaviour soon evolved into delivery of a broad range of personal and social development services including accredited educational courses (BTECs, AQA, OCN); and healthy eating, environmental, and enrichment programs within schools (Djohari 2011). GHOF engaged with a diverse range of young people, the majority of whom had multiple needs and difficult home lives. This included those referred to the programmed with ADHD, anxiety disorders, or depression; self-harmers; young carers; witnesses to domestic violence; the bereaved; whose parents were in prison or substance misusers; and those living in care (Djohari 2011). The majority of the young people at the four case study sites were white 'working class' males, reflecting the location of the projects in northern communities considered to be within the top 10 most deprived in England, and the gendered perspectives of the professionals who referred young people to the programs (Djohari, Brown and Stolk 2016).

The majority of GHOF's work concurred with general youth work practices and involved the introduction of positive peer groups, mentoring support, activities aimed at building confidence and self-esteem, developing a sense of 'belonging', and identifying potential career paths. In this paper, we focus on how angling shapes young people's relationship with the more-than-human world and how the affectual spaces of angling emerge and are used in young people's coping practices beyond the planned 'outcomes' of managed intervention sessions.

Conducting research in spaces young people used to 'escape' inevitably influenced fieldwork practice. Intervention staff frequently described angling as a 'tool', explaining that the 'calming quality' facilitated sensitive or emotive discussions. We observed that when young people became agitated they re-focused on technical tasks, took a breath and gazed at the water. Were they listening, thinking or focusing on angling? The ambiguity to this response (or lack of it) was accepted by young people 
and staff as a legitimate part of waterside interactions. This removed any pressure for young people to reflect or respond immediately to the difficult issues raised. Coaches consequently coproduced these safe discursive spaces, using the time afforded by angling to build unhurried supportive relationships.

When a researcher joins the waterscape they become privy to this space. Because young people are primed to talk about complex emotions with intervention staff there is potential for over disclosure. Ethnographers have traditionally taken advantage of being present in interlocutors' worlds to become the person others tell things to. But in locating research in angling spaces, young people wrested back some control. Firstly, mirroring young angler's rhythmic relationship with(in) angling waterscape, the discussions between young people and researcher were not always direct. Conversations moved at the pace of the water, they flowed and paused and pooled, only to resurface again at a later time. Conducting an waterside interview with a young person could take a whole day as they moved in and out of focused attention, performing activities or refocussing on their fishing.

These types of shifted attention practices are quite common to both youth work and participant observation where 'conversations' emerge alongside participants focused on an activity. In angling this time is stretched, slipping into a rhythm of activity and focus dictated as much by the environment as young people themselves. Most significantly, because angling practice is rhythmical, we found that young people were able to disengage from the research without needing to make an obvious statement; they simply refocused attention back on the task at hand. In this way young people controlled the pace of engagement. As Valentine (1999) cautions, research consent should be understood as an ongoing process. It takes a confident young person to say they do not want to participate anymore. More commonly they will subtly 
withdraw consent through 'messing around', and as long as the setting facilitates it, through walking off or becoming distracted by something else. Angling allows for a less confrontational way to disengage because young people are not stepping away from the research but folding it into the flow of angling practice.

Secondly, young people utilised the affective quality of angling/space to still intense emotions, shifting from talk to focus on fishing tasks in order to regulate their feelings. Young people often shared troubled histories without anger; they expressed sadness or regret without agitation; and communicated melancholy reflections. Coupled with the slow time-stretched pace of discussions, young people managed overwhelming emotions to effectively communicate what they wanted to explain but frequently found difficult to express. When attempting to discuss similar themes in other locations (schools, youth clubs) young people were more agitated, walking around, 'messing' with each other, more animated, more posturing. At the waterside, even in group discussions, they were reflective. To understand young anglers' use of these waterscapes to manage feelings, we need to understand what angling is: how it shapes the relationship between anglers and the environment, and how engagement in angling practice 'weaves' affectual space into being.

\section{The practice of angling and the 'weaving' of affectual space.}

I first went fishing when I was about 10 years old. From the first time the float slipped under I have been addicted. Most of my friends play football, but give me time by the lakeside any day. There you can have time to be alone and be close to nature...I have had some amazing moments in just these 5 years of fishing. I have seen a heron dive in and catch fish only metres away from me, I have had a minnow that managed to get hooked despite that fact that my bait was a whole earthworm...I've seen huge carp warming themselves in shallow water that was inches deep and I've even caught a fish even when the bait had come off my hook...It has given me the opportunity to experience an evening beside a lake in 
summer, to watch the sun set and to feel like the day could not have been better spent any other way. (Male 15) $)^{3}$

There is an aesthetic to angling that incorporates nature, observations, stillness and being 'present' in one's environment. Although tempting to interpret such narratives as the outcome of immersion into 'naturally' beautiful surroundings, it is more productive to read these descriptions as articulations of 'being-in-the-world' felt through the practice of angling. These poetic expressions describe a relationship with(in) the world and can emerge even about unsightly places. On one visit we met a local councillor who was immensely proud of the therapeutic role local waters played in his community. He spoke in such glowing terms that we were dismayed to find a small concrete pond, completely surrounded by paved edging, splattered in bird droppings with no grassy banks or vegetation in sight. And yet to the anglers young and old that frequented it, this was arcadia, where the fish rippled and gleamed through the water, and the birds called overhead.

We need to be careful then not to over romanticise the angler experience. Many anglers use technology, have access to fisheries that provide wifi, order pizza to their locations, sit in padded chairs, and frequent waters that have more in common with intense farming than highland wildernesses. All the while they narrate an atavistic vision of anglers as hunter gathers caught in the ultimate struggle of man versus nature. Bull (2011) has illuminated such schisms, describing how the bodies of fish become embroiled in how anglers and environmental professionals (such as Environment

\footnotetext{
${ }^{3}$ This quote and others first appear in the project report Djohari 2011 and on the research website http://www.resources.anglingresearch.org.uk/
} 
Agency officers and river conservationists) express and think about everything from water quality, wildness, nature, and angling as an anti-modern endeavour.

Among anglers young and old, the experience of being in angling waterscapes is described as an immersive practice: 'a means of gathering stillness both inside and outside the body' (Macnaghten 2003, 75). Siebers et al's (2014) study of fishing in youth work has attempted to account for this 'interior world'. Drawing on angler interviews alongside literary texts and auto-ethnography, they understand the 'stillness' of angling as contemplation, mindfulness and wisdom. However, we found contemplation to be most vocalised by adult anglers, and a review of Siebers et al's video footage (http://spsheff.wixsite.com/fishingaswisdom) similarly demonstrates that young people spoke more about changes in feelings states rather than angling as 'thinking time'. So how do we attune ourselves to young people's experiences?

Sidestepping the issue of interpretation and 'meaning', we followed young people's lead and focused on 'being-in-the-world'. To provoke reflection on the environment in young people's angling practice, we asked: 'would it be the same to go fishing in a swimming pool?' Young people frequently cited the 'buzz' of catching, and for younger children 'touching the fish', as appealing elements of angling. Yet, although they acknowledged these experiences could be recreated in a swimming pool, there would be 'something' missing. The consensus was angling was also about 'being in nature' and 'being outdoors'. These were felt experiences that wove together the thrill of 'the fight' and the 'rush' of the catch, with opportunities to sit or stand, to become still, to really observe the world around them, and spend time just 'being' present.

As Ingold (2000) explains, meaning is derived not from the imposition of symbolic frames on the world from outside but grows up through being-in-the-world. The transformative effect of this is captured by Eden and Bear: 'Anglers do not merely 
react to water, but through angling they become different sorts of humans from others [non-anglers]' (Eden and Bear 2011, 298). They see and feel those features of the environment made meaningful by their craft, such as changes in air pressure, the pattern of surface bubbles, or a hatch of mayflies, which may be unremarkable to non-anglers. They start to read waterscapes through their details, making mental notes of gullies, the banks of rough ground, or deposits at low tide that indicate where fish lurk. Eden and Bear (2011) describe this practice of reading an ever evolving environment as 'watercraft'. It is knowledge passed angler to angler through coaching instruction, bankside banter, and magazines or internet forums. But it is also discovered directly through experience, experimenting with baits or flies and observing how fish respond in their particular stretch of water. Anglers consequently develop their skills through the co-construction of knowledge with other anglers and an intimate relationship with their own fishing location (Djohari, Brown and Stolk 2016). They learn the technicalities of how to fish and to read the water more generally but they 'know' best those places in which they dwell.

Studies of human and non-human relationships have frequently drawn on relational, phenomenological and non-representational approaches in recognition of how animals, plants and humans inhabit the world together (Buller 2015; Lornimer 2006). In relation to children and young people, drawing on the post-humanist works of Deleuze and Guttari (1981) and Latour (1993), this has led scholars to re-theorise childhood beyond the human-centric models found in the child development and social construction theories (Taylor, Pacinini-Ketchabaw, and Blaise 2012, 82). Childhood can consequently be thought of as a series of assemblages of human and non-human (Prout 2005), opening rich avenues for rethinking children and young people's relationship with the 'natural' world. 
While this paper does not focus specifically on the ways young anglers, the fish and environment co-create ways of knowing, being and acting together it does nonetheless recognise that to understand the angler experience one has to loosen the human centric bias and appreciate how the non-human co-creates what it is to fish and be a fisherman (Bear and Eden 2012). In angling fish are one of many participants in a 'community of practice' that is the 'evolving, continuously renewed set of relations' through which knowledge is built, sustained and shared between practitioners' (Lave and Wegner 1991, 50). Angler knowledge transforms as the fish, local wildlife and greenery adapt and take advantage of angler activity. In turn through 'thinking like a fish', anglers start to respond and adapt to the rhythms of the environment, transforming their own practice to match the fish's own time-spaces (Bear and Eden 2012). Angler knowledge and behaviour is subsequently in a continued process of renewal formed in the rythmpatterns and the push and pull of their non-human partners. Angling makes no sense then without the wider ecologies of the waterscape. This is why young people are perplexed with the swimming pool question. Even while they struggle to articulate it, the message is clear: They look at us as if we are being absurd. You can't fish a swimming pool! It's just not the same.

Learning to be-in-the-world as an angler is about knowing, being and acting with(in) waterscapes. This includes relational, embodied practices that 'weave' the world into being. Just as 'watercraft' is a learned activity co-created with others, so too are the embodied practices of angling. Everything from learning to cast, to reading and interpreting the visual and sensorial vibrations to determine the time to strike, is a learned bodily relationship with(in) the world cultivated by angling coaches and repetition. When young people first fished they were eager to be 'doing' things: continually throwing in maggots to attract fish to their line, or reeling in only to cast out 
again. The coaches would remind them to be still. Too much food disturbs the water. They needed to sit and wait: 'watch the float'. With practice and guidance young people slowly built sustained focus, until they could wait in stilled anticipation. In a full day's fishing we could observe this transition from the need to be moving to eventual focus and stillness. A few missed bites were incentive to hold attention for longer stretches until one was rewarded with the thrill of a catch.

To understand angling we need to appreciate these elements as part of a 'phenomenal whole' (Wetherall 2012, 85): the fluidity of embodied movement in casting a fly line 7-10 meters behind you; the tension of holding steady a 3-18 meter pole into a lake; the stillness of a body held in readiness and anticipation; reading the water, focusing, feeling for vibrations; the sudden adrenaline rush of a catch; then just as quickly holding excitement in check to gently unhook a fish and return it safely to the water or 'dispatch' of it humanely. Understanding angling as these 'strings of present moments' (Wetherall 2012, 85), explains how angling becomes totally absorbing and begins to explain its relevance for young people's coping strategies.

Coaches and adult anglers would frequently explain angling as contemplation, musing that it gave young people time to reflect on their lives. Hoping to get further clarification, we asked young people what they thought about when fishing. The most common answer was they thought about 'nothing'. More probing generally resulted in technical answers: I'm watching the water; I might think about what bait to try next; I don't really think about anything. 'I just sit there and look at the end of my line until I've caught one and then I reel it in'. This was frustrating as it was initially unclear if it was an attempt to disengage with the researcher. Only through observation and building our own experiential knowledge, did we begin to understand that both answers, thinking and not thinking, were true for angling. Acknowledging our bodies as research tool 
(Woodyer 2008) we lost hours in a day fly-fishing without the stream of thoughts and mental list making invading our consciousness. We felt the physical strain of maintaining the stillness of a coarse fishing pole, and felt the pull of anticipation that keep focused attention on the tip of a rod less we missed a bite.

To the outside observer angling appears to involve 'doing nothing' but waiting. But for participants 'waiting' is itself a form of 'doing': it is an act of attunement, mentally and bodily adjusting to the ongoing stimuli of the present. One reads the visual and sensorial cues, preparing the body to strike. There is no room for other thoughts when the mind/body is completely focused on the task. Moreover, it is a somatic experience: heart rate and breathing slows; one learns to keep focus without straining; the body relaxes into stilled readiness. Each fishing event sediments these patterns, so that the body attunes to the rhythm of casting and focused attention with less and less need for conscious attention. Although the rhythm of angling can allow for mind drifting and reflection on one's life, young people told us that angling also allowed them to $\underline{\text { not }}$ think about their worries. Through fishing young people could enter into a 'flow' state (Anderson 2012) where the 'fascination' of attention (Kaplan 2001) and the concentration required muted out all other thoughts. In this way young people 'got away' not just physically but mentally. It is difficult then to untangle the somatic, embodied quality of angling practice from the affectual space of 'being' at the waterside because for young anglers, the affectual dimension of angling waterscapes is emergent in the practice-centred becomings of these spaces (Anderson 2012). Even when not fishing young anglers 'dwell' at the pond, they synchronise with the rhythm patterns of the waterscape, they read the water, they become still, the body relaxes. 


\section{Transforming feelings: waterscapes and young people's coping strategies.}

Waterscapes matter in young anglers' lives as part of their coping practices, visiting angling spaces to regulate their emotion and change feeling states. Young people most frequently described angling as an escape, a means of 'getting away'.

[It's] just like being away from everyone, you're just at a lake, nice and quiet. You can just relax...that's what I love, just being a round loads of fields, not hearing sirens all the time. (Male 18, London)

'Getting away' encompassed physical removal from a stressful environment and a mental break. This could include escaping from busy households or arguments, to finding bankside space to do homework. In relation to 'getting away' the place did matter. Talking with young people and journeying with them to fishing venues, we discovered a local landscape made meaningful as 'sites visited' and as 'potential' fishing venues. Young people navigated them both by how they felt and what they needed from their fishing experience: to 'get away' somewhere quick and local; somewhere affordable; somewhere with more of a challenge; somewhere social to hang out with others; somewhere to be on their own; somewhere other anglers would intervene if there was trouble; somewhere 'safe' from the threat of crime.

But 'getting away' was not just about a physical relocation. In James' cases 'getting away' meant escaping exam pressure. His mother explained that James had ADHD and Asperger's:

From the age of 8, I wanted to kill him, because he was hypo, naughty, nasty, out of sheer desperation levels dad took him out fishing one day and he phoned me up, and said, you've got to come down and see this.

She went on to describe how James was not twitching or fidgeting but sitting perfectly still watching the float. 
From that day on, especially when he was feeling stressed, but especially when he was doing his GCSE's in school, rather than do revision, he used to do a 4-5 hour fishing session, just relaxing and getting away, chill out and then he was quite happy about going into school.

James' experience illustrates how young people proactively use angling and the associated waterscapes to remove themselves from stressful environments and transform feeling states. We are in no doubt, through our observations, young people's comments, and the reflection of parents, teachers and intervention practitioners, that angling matters to young people because they are able to manipulate the affective quality of being in angling spaces to manage their distress.

I love fishing. You know when you're at home and you're angry and that, you know when you're really annoyed with someone, you come down set up a rod, chuck it in, bring you're radio out, your snack, you're sorted right, just chill out. (Male 18)

It is the combination of total absorption and 'being away' from pressures which young people highlight as affecting. Peter (13) talked about his anxiety in class. He was "not a lad who got in to trouble' he told us. Instead he was 'dead quiet'; he did not speak much and had panic attacks at school.

Fishing relaxes me so much. I used to get panic attacks in year 7. And now I'm dead relaxed. It's weird because I used to have panic attacks at school, and then one day I just couldn't breathe, and the next day I was with GHOF again and I was fine. It happens when I have something on my mind to do, coming to school. Whereas tying hooks and all that, having something to do where I'm just sitting here, something to relax. It calms me down. (Male 13, GHOF)

For these young people angling is experienced as the dissipation of anger, tension and anxiety. They actively utilise this to manage and control how they are feeling, getting 
out of the house and escaping to the water when they need to 'get away' or 'cool down' before they got into arguments or 'something worse'.

Each time a young person flees a stressful situation to seek the comfort of the river they reinforce waterscapes as affectual, restorative spaces. As Jones explains '...our dealings with(in) the present rest upon our always-at-work memories and stocks of experience to script our responses and actions' (Jones 2011b, 5). This includes not only our bodily repetitions, but how waterscapes are co-woven in the presence and absence of socially meaningful others. Even as places emerge and are experienced through 'being-in-the-world', they are not divorced from the broader assemblages of social relationships and memory. In Lee and Irving's paper in this Special Issue, children frequently describe their routes through the surrounding fenland alongside memory of previous family visits there. Likewise when young people talk about angling or the places they fish, expressions of place are entangled with kin relationship. Fishing with young people on a bleak Northumberland beach, one mentioned that his dad and grandfather fished this coastline but he had never accompanied them. He was 15 and we suspect had been old enough to take these trips for some time, but angling represented a leisure activity for 'older' men, often staying out over night with or without a few beers. These types of asides frequently emerged in angling discussions as expressions of fissures in the relationships between young people and their parents or extended families.

Being-in-the-world with others particularly matters when there is a history of negative or absent shared experiences. Ethan's example illustrates this. Ethan (16) had been a peer mentor at one of the projects for 3 years. After almost a year of field visits, he finally expressed an interest in the research and told us more about his life ending with a description of fishing in relation to his family. 
All my family has been into fishing, just not me or my dad. And my dad's into it now because of me...Yeah, all my family has been into fishing, my granddad and that. I haven't seen him [granddad] for ages but we are supposed to be going fishing with them soon. Just out with all the lads. They see match men as amazing at fishing, and for me to have been fishing for a year or two, and they found out I'd been fishing matches when my dad said, and they've been like "what?!" [Wow!]. So I'm going out with them soon, just to show off basically.

When Ethan explained his father had started angling because of him, he was describing a shared activity emergent from a historically troubled relationship. Speaking with his father at an earlier session we had learnt that the relationship with Ethan and his family had become strained. He explained that Ethan was diagnosed with ADHD and Asperger's as a child. He had been expelled from primary school multiple times and his behaviour had become violent. In one incident Ethan had smashed up his uncle's sofa and torn the arms off. His father explained that he had split from his wife, not too amicably, and Ethan went on to live with him. Caring for Ethan had become a full time role and he had given up his job. Ethan's father disclosed that he had become desperate and for a fleeting moment had thought the 'unthinkable' and consider giving Ethan up. Then they had found GHOF and fishing, and it had calmed Ethan down. He started taking Ethan fishing, finding it a good way to spend time together, and then having sat next to him for a while he decided to take up fishing and it became something they could $d o$ together: something to bond over, something they could re-build a relationship with.

For families experiencing relationship difficulties, angling emerges as an opportunity to 'get away' from the arguments together, to share in the excitement of a catch, and sit and just 'be' in mutually enjoyable silence. Young people expressed these renewed familial relationships obliquely: describing the fishing venues they had visited together; how a father took photos of angling venues he visited to share when they next 
met; how relatives had given them old equipment, or saved to buy them a particular rod or reel. Accounting for the assemblages that bring angling spaces into being consequently describes a time-deep set of trajectories; intersections of memories and experiences. Their 'mattering' comes from the silent companionship of co-weaving the bankside world into being together situated within the shared history and felt experience of their prior relationships.

\section{Conclusion:}

Investigating the affectual dimension of children's geographies remains important for advancing understanding of why places 'matter' to young people. This is particularly true for understanding the role of affectual geographies in young people's coping strategies: how certain 'places' and practices become significant because of how they make a young person 'feel' even if they cannot fully articulate why. By focusing on being-in-the-world and the embodied practice of angling as world 'weaving', this paper demonstrates how affectual places are continually made present through young people's active engagement with(in) the world. It is not enough then to sit a young person down by a pond and expect their anger and anxieties to dissipate. This is because it is not their physical presence within the 'natural' environment that is necessarily affecting but how one interacts with it: the watercraft that integrates a person into the rhythmpatterns of waterscapes, fascinating the attention with a world of sights, sounds and sensations; and the hours of angling coaching and practice that enables one to focus, still the body and quite other thoughts. It is this unfolding practice-centered relationship between human and non-human agencies that bring the affectual experience of waterscapes into being for young anglers.

We need to be cautious then of uncritically applying biophilia or 'nature deficit' assumptions when thinking about young people's relationships with the affectual spaces 
'found' in nature. If affectual places and the comfort derived from them are made present through young people's active interactions with(in) the world, then we cannot assume there will be a uniformity of therapeutic or restorative experiences from immersion in green/blue spaces. Instead we must investigate how and why affectual places come into being and for whom. Significantly, this also requires acknowledging those assemblages that originate in the past (memories and repetition) and the role of others in co-weaving affectual spaces. It is too easy for a phenomenological focus on the body, being/becoming-in-the-world and affect, to foreground the individual and tend towards presentism. To understand why angling waterscapes 'matter' to young anglers, we need to acknowledge a shared trajectory of past 'felt' experiences, the arguments, the frustrations, and ruptured relationships, that adds significance to the silent companionship felt in weaving waterscapes into being together.

As a final thought, if we understand restorative spaces as 'practice-cantered becomings' woven though young people's ongoing interaction with(in) the world, then we might want to continually reassess our research locations. How might we better accommodate young people's coping practices with(in) research sites? How might personal histories and experiences combine to make research spaces safe or comforting for some and not for others? If we continue to invite young people to tell us about lives that might be distressing, do we not have a responsibility to consider how the affective geographies of children and young people can be woven into the 'safe spaces' of our research sites?

\section{Acknowledgements}

We would like to thank the Environment Agency, Angling Trust, Get Hooked on Fishing, Angling Development Boards of England and Scotland, and Dr Liz Oughton from Newcastle University (|UK) for their support. We would also like to thank the young people who graciously shared their experiences with us. 
Anderson, Jon. 2012. "Relational places: the surfed wave as assemblage and convergence”. Environment and Planning D: Society \& Space 30 (4): 570-587

Bear, Christopher and Sally Eden. 2012. "Thinking like a fish? Engaging with nonhuman difference through recreational angling". Environment and Planning D: Society and Space 29: 336-352.

Brown, Adam, Natalie Djohari and Paul Stolk. 2012. Fishing for Answers: The Final Report of the Social and Community Benefits of Angling Project. Substance. Available at: http://resources.anglingresearch.org.uk/project_reports/final_report_2012

Bull, Jacob. 2011. "Encountering fish, flows, and waterscapes through angling". In Environment and planning A 43: 2267-2284.

Buller, Henry. 2015. “Animal Geographies II: Methods”. Progress in Human Geography 39 (3) 364-384.

Casey, Edward S. (2001) "Between Geography and Philosophy: What Does It Mean to Be in the Place-World?" Annals of the Association of American Geographers 91(4): 683-693.

Csordas, Thomas, J. 1994. "Introduction: the body as representation and being-in-theworld". In Embodiment and Experience. The Existential ground of culture and self, edited by Thomas Csordas, 1-24. Cambridge: Cambridge University Press.

Dalby, Simon. 2007. "Anthropocene geopolitics: globalisation, empire, environment, and critique." Geography Compass 1 (1): 103-118.

Deleuze, Gilles and Félix Guattari. 1981 A Thousand Plateaus: Capitalism and Schizophrenia. Minneapolis: University of Minnesota Press.

Djohari, N, Brown, A and Stolk, P. 2016. "The one that got away': how angling as a culture of practice manifests in the teaching and learning relationship within angling-based intervention programmes". Ethnography and Education 11 (1): $40-56$.

Djohari, Natalie. 2011. The 'Added Value' of Angling Intervention Programmes. Manchester: Substance. http://resources.anglingresearch.org.uk/project_reports/interim_reports_2011

Eden, Sally and Christopher Bear. 2011. 'Reading the river through 'watercraft': environmental engagement through knowledge and practice in freshwater angling”. Cultural Geographies 18(3): 297-314 
Hartig, Terry, Anders Böök, Jörgen Garvill, Tommy Olssen, Tommy Gärling. 1996.

"Environmental influences on psychological restoration". Scandinavian Journal of Psychology 37: 378-393

Heidegger, Martin. [1953] 2010. Being and Time. New York: State University of New York Press.

Hill, Jacquetta and David Plath. 1998. "Moneyed Knowledge: How Women Become Commercial Shellfish Divers". In Learning in Likely Places: Varieties of Apprenticeships in Japan, edited by John Singleton, 211-25. Cambridge: Cambridge University press.

Hine, Rachel, Jo Peacock and Jules Pretty. 2008. "Care farming in the UK: context, benefits and links with therapeutic communities." In Therapeutic Communities 29:245-60.

Hopkins, P. and Pain, R. (2007) "Geographies of age: thinking relationally". Area 39 (3): $287-294$.

Horton, John and Peter Kraftl. 2006. "What else? Some more ways of thinking and doing 'Children's Geographies”. Children's Geographies 4(1): 69-95.

Horton, John and Peter Kraftl. 2008. "Reflections on geographies of age: a response to Hopkins and Pain". Area 40 (2): 284-288.

Horton 2010. “"The best thing ever': how children's popular culture matters”. Society and Cultural Geography 11(4): 378-398.

Ingold, Tim and J Lee Vergunst,. 2008. Ways of walking. Ethnography and practice on foot. London: Routledge

Ingold, Tim. 2000. The Perception of the Environment. Essays in livelihood, dwelling and skill. London: Routledge.

Jones, Owain. 2011a. "Lunar - solar rhythmpatterns: towards the material cultures of tides". Environment and Planning A 43: 2285 - 2303.

Jones, Owain. 2011b. “Geography, memory and non-representational geographies”. Geography Compass 5 (12): 875-885.

Kaplan, Stephen. 2001. "Meditation, Restoration and the Management of Mental Fatigue". Environment and Behavior 33: 480-506.

Keller, Charles and Janet Dixon Keller. 1993. "Thinking and Acting in Iron”. In Understanding Practice: Perspectives on Activity and Context, edited by Seth Chaiklin and Jean Lave, 125-143. Cambridge: Cambridge University Press. 
Kellert, Stephen R and Edward O Wilson. 1993. The Biophilia Hypothesis.

Washington: Island Press

Latour, Bruno. 1993. We Have Never Been Modern. Cambridge, MA: Harvard University Press.

Lave, Jean and Etienne Wenger. 1991. Situated Learning: Legitimate Peripheral Participation. Cambridge: Cambridge University Press.

Lornimer, Hayden. 2006. "Herding memories of humans and animals". Environment and planning D: society and Space 24: 497-518.

Louv, Richard. 2008. Last Child in the Woods. Saving our children from nature deficit disorder. North Carolina: Algonquin books of Chapel Hill.

Macnaghten, Phil. 2003. "Embodying the environment in everyday life practices". The Sociological review 51: 63-84.

Merleau-Ponty, Maurice. [1945] 2014. The Phenomenology of Perception. London: Routledge.

Milligan, Christine and Amanda Bingley. 2007. "Restorative Places or Scary Spaces: The impact of woodland on the mental wellbeing of young adults". Health and Place 13(4): 799-811.

O’Connor, Erin. 2007. "Embodied knowledge in glassblowing: the experience of meaning and the struggle towards proficiency". The Sociological Review 55, Issue Supplement S1: 126-141.

Pretty, Jules, Rachel Hine and Jo Peacock. 2006. "Green exercise: The benefits of activities in green places". The Biologist 53(3): 143-148.

Prout, Alan. (2005) The Future of Childhood. New York: Routledge.

Pyyry, Noora. 2016. "Participation by being: Teenage girls' hanging out at the shopping mall as 'dwelling with' [the world]”. Emotion, Space and Society 18: 9-16.

Rautio, Pauliina and Päivi Jokinen. 2015. “Children's Relations to the More-ThanHuman World Beyond Developmental Views”. In Play, Recreation, Health and Well Being, Geographies of Children and Young People 9, edited by Bethan Evans, John Horton, and Tracy Skelton. Singapore: Springer.

Siebers, Johan, Kate Pahl, Richard Steadman-Jones, Steve Pool, Marcus Hurcome, Andrew McMillan, Hugh Escott. 2014. Connected Communities. Communicating Wisdom: An Arts and Humanities-based Study of Fishing in Youth Work. Final Report. 
Soja, Edward. 1996. Thirdspace: Journeys to Los Angeles and Other Real-and-

Imagined Places. Oxford: Wiley-Blackwell.

Strang, Veronica. 2015. Water: Nature and Culture. London: Reaktion Books.

Tarrant, Anna. 2010. "Constructing a social geography of grandparenthood: a new focus for intergenerationality". Area 42 (2): 190-197.

Taylor, Affrica; Veronica Pacinini-Ketchabaw and Mindy Blaise. 2012. “Children's Relations to the More-than-Human World". Contemporary Issues in Early Childhood 3 (2): 81-85.

Thrift, Nigel. 2004. "Intensities of feeling: Towards a spatial politics of affect". Geografiska Annaler 86 B (1): 57-78.

Valentine, Gill. 1999. "Being seen and heard? The Ethical complexities of working with children and young people at home and at school". Philosophy and Geography, 2 (2): $141-155$

Vanderbeck, Robert. 2007. "Intergenerational Geographies: Age Relations, Segregation and Re-engagements. Geography Compass 1(2): 200-221.

Vannini, Phillip and Jonathan Taggart 2014. "The day we drove on the ocean (and lived to tell the tale about it): of deltas, ice roads, waterscapes and other meshworks", In Water Worlds: Human Geographies of the Ocean, edited by Jon Anderson and Kimberley Peters, 89-102. London: Routledge.

Wetherell, Margaret. 2012. Affect and Emotion. A new Social Science Understanding. London: Sage.

Woodyer, Tara (2008) "The body as research tool: embodied practice and children's geographies". Children's Geographies 6(4): 349-362. 